\title{
The BOLD correlates of the visual P1 and N1 in single-trial analysis of simultaneous EEG-fMRI recordings during a spatial detection task
}

\author{
N. Novitskiy ${ }^{\text {a,* }}$, J.R. Ramautar ${ }^{\text {a,b }}$, K. Vanderperren ${ }^{c}$, M. De Vos ${ }^{c}$, M. Mennes ${ }^{\text {b,d }}$, B. Mijovic ${ }^{\text {, }}$, B. Vanrumste ${ }^{\text {c,e }}$, \\ P. Stiers ${ }^{\text {f }}$, B. Van den Bergh ${ }^{\text {d,g,h }}$, L. Lagae ${ }^{\text {b }}$, S. Sunaert ${ }^{\text {i }}$, S. Van Huffel ${ }^{\text {c }}$, J. Wagemans ${ }^{\text {a }}$ \\ a Laboratory of Experimental Psychology, Katholieke Universiteit Leuven, Leuven, Belgium \\ ${ }^{\mathrm{b}}$ Department of Pediatric Neurology, Katholieke Universiteit Leuven, Leuven, Belgium \\ c Department of Electrical Engineering, ESAT-SCD, Katholieke Universiteit Leuven, Leuven, Belgium \\ d Department of Psychology, Katholieke Universiteit Leuven, Leuven, Belgium \\ e Biosciences and Technology Department, Katholieke Hogeschool Kempen, Geel, Belgium \\ ${ }^{\mathrm{f}}$ Faculty of Psychology and Neuroscience, Maastricht University, Maastricht, The Netherlands \\ ${ }^{g}$ Department of Psychology, Tilburg University, Tilburg, The Netherlands \\ ${ }^{\mathrm{h}}$ Department of Welfare, Public Health and Family, Flemish Government, Brussels, Belgium \\ ${ }^{i}$ Department of Radiology, Katholieke Universiteit Leuven, Leuven, Belgium
}

\section{A R T I C L E I N F O}

\section{Article history:}

Received 17 June 2010

Revised 29 August 2010

Accepted 16 September 2010

Available online 30 September 2010

\begin{abstract}
A B S T R A C T
Simultaneous EEG-fMRI measurements can combine the high spatial resolution of fMRI with the high temporal resolution of EEG. Therefore, we applied this approach to the study of peripheral vision. More specifically, we presented visual field quadrant fragments of checkerboards and a full central checkerboard in a simple detection task. A technique called "integration-by-prediction" was used to integrate EEG and fMRI data. In particular, we used vectors of single-trial ERP amplitude differences between left and right occipital electrodes as regressors in an ERP-informed fMRI analysis. The amplitude differences for the regressors were measured at the latencies of the visual P1 and N1 components. Our results indicated that the traditional eventrelated fMRI analysis revealed mostly activations in the vicinity of the primary visual cortex and in the ventral visual stream, while both $\mathrm{P} 1$ and N1 regressors revealed activation of areas in the temporo-parietal junction. We conclude that simultaneous EEG-fMRI in a spatial detection task can separate visual processing at 100$200 \mathrm{~ms}$ from stimulus onset from the rest of the information processing in the brain.
\end{abstract}

(C) 2010 Elsevier Inc. All rights reserved.

\section{Introduction}

Human perception is a fast yet multi-component process. In the first 300-400 ms after stimulus onset our brain manages to fully analyze a stimulus and to react to it. Different stages of that processing can be analyzed with event-related potentials (ERPs), a technique with millisecond time resolution. On the other hand, functional magnetic resonance imaging (fMRI) provides excellent space resolution but is not sensitive to the fine-grained time-course of information processing. The fact that fMRI and EEG share common neural sources (Logothetis et al., 2001) supports the assumption of common information in EEG and fMRI datasets. For these reasons, simultaneous EEG-fMRI measurements hold potential to provide optimal temporal and spatial resolution to disentangle the processes of early visual perception.

Previous studies successfully used checkerboard stimuli to check feasibility of ERP recordings in the hostile MR scanner environment (Assecondi et al., 2010; Becker et al., 2005; Bonmassar et al., 2001;

\footnotetext{
* Corresponding author.

E-mail address: kolja.novitski@med.kuleuven.be (N. Novitskiy).
}

Sommer et al., 2003; Vanderperren et al., 2010). We suggest that checkerboard stimuli can be also used to develop EEG-fMRI data integration techniques. Given that retinotopy is the basic principle of visual cortex organization (Di Russo et al., 2002; Tootell et al., 1997), spatial location is the most obvious manipulation of peripheral visual stimuli in ERP as well as in fMRI studies.

Temporal course and spatial distribution of brain activity to presentation of peripheral circular checkerboard stimuli were extensively studied by combining fMRI and EEG data from separate sessions (e.g., Di Russo et al., 2002, 2003, 2005). The visual ERPs in the interval up to $160 \mathrm{~ms}$ from stimulus onset could be fully explained by a combination of 7 dipoles in primary visual cortex (V1), extrastriate visual areas (both in the dorsal and ventral streams) and in the parietal areas. Among ERP components, P1 around 80-110 ms and the posterior $\mathrm{N} 1$ at 150 and $180 \mathrm{~ms}$ were explained by the activity in the dorsal stream in the vicinity of V3 (Di Russo et al., 2003, 2002). In those studies fMRI activations were remarkably close in space with these dipole locations. However, in another study from the same group the area MT activation in the fMRI data to pattern reversal stimuli did not fully correspond to any of the observed ERP dipole locations (Di Russo et al., 2005). 
When there is a discrepancy between fMRI and EEG activation, comparison of independently analyzed fMRI and EEG can only reveal but not explain it. fMRI activations can be used as seeds for ERP dipole localizations (Bledowski et al., 2004). The obvious limitation is that instead of extracting common information, the information is forced from one method onto another. Parallel analysis of EEG and fMRI obtained in separate sessions can be performed with so-called joint independent component analysis (jICA; Calhoun et al., 2006). Two concerns drive the application of the simultaneous EEG-fMRI recordings. Firstly, physical environment, arousal state and attention level of the experimental subject can be very different in EEG and fMRI recording sessions (Debener et al., 2006, 2005). Secondly, only simultaneous recording allows combination of fMRI and ERP information on a single trial level. The approach chosen in this study is to take individual trial ERP measures as regressors in fMRI analysis. This variety of EEG-informed fMRI analysis was named "integration by prediction" (Kilner et al., 2005). A detailed review EEG-informed fMRI analyses is available elsewhere (Debener et al., 2007b; Ullsperger, 2010).

Integration-by-prediction usually includes several steps. First, the ERP components of interest are selected. The number of ERP components of interest varies in different studies: it can be one (Benar et al., 2007; Debener et al., 2005; Mulert et al., 2008; Warbrick et al., 2009), two (Karch et al., 2010; Mayhew et al., 2009) or three (Eichele et al., 2005). Second, the electrode of interest is selected, usually the one that yields the largest amplitude of the pre-selected component. Usually one electrode is selected for the measurements (Benar et al., 2007; Karch et al., 2010; Mayhew et al., 2009; Mulert et al., 2008; Warbrick et al., 2009) but regions of interest (Eichele et al., 2005) and back-projected IC topographies (Debener et al., 2005) have also been used. Third, the independent variable is selected on the basis of the research question. The amplitude of the ERP component usually serves as an independent variable in the regressor construction, but many other possible features can also be selected, such as of the ERP latencies in individual trials. Fourth, EEG data should be preprocessed in order to improve the signal-to-noise ratio for the single trial measurement. The preprocessing may be extensive data filtering in a narrow frequency band (Benar et al., 2007; Debener et al., 2005) that is accompanied or substituted by more sophisticated clean-up of the data, such as independent component analysis (ICA, Debener et al., 2005; Eichele et al., 2005) or wavelet analysis (Eichele et al., 2005; Mayhew et al., 2009; Warbrick et al., 2009). Fifth, the spurious correlation between the different measures in the same trials should be addressed. In the majority of the studies the ERP regressors are made orthogonal to other regressors using the Gram-Schmidt procedure (Debener et al., 2005; Eichele et al., 2005; Karch et al., 2010; Mulert et al., 2008; Warbrick et al., 2009). As the sixth and final step, the ERP regressor is usually convolved with the hemodynamic response function (HRF). Alternatively, to estimate the HRF, a deconvolution of the fMRI signal can be used instead of a convolution of the EEG signal (de Munck et al., 2007; Eichele et al., 2009; Wu et al., 2010).

Integration-by-prediction analysis can functionally dissociate brain areas that are activated together according to the traditional fMRI analysis. For example, Debener et al. (2005) looked at errorrelated negativity (ERN)-an ERP component indicative of subject error in the task. Integration-by-prediction analysis demonstrated that the cingulate gyrus was the only ERN-related area among a set of activations revealed by traditional fMRI analysis. Similarly, in the study of Eichele and colleagues (Eichele et al., 2005) the integrationby-prediction analysis of different ERP components in the auditory oddball task (P2, N2 and P3) produced fMRI activations maps that were non-overlapping with each other and the map from traditional fMRI analysis.

In our study we wanted to use the integration-by-prediction technique to dissociate the activity associated to the visual P1 and N1 components from the other activations in the traditional fMRI analysis. In our version of the integration-by-prediction analysis we used ten occipital electrodes. We measured amplitude of visual P1 and N1 as independent variable. Gram-Schmidt orthogonalization and convolution with HRF were applied as in the previous studies. The novelty of our paradigm was in the paradigm-informed signal-to-noise improvement. Namely, we used the fact that peripherally presented visual stimuli P1 and N1 have larger amplitude over the contralateral side of the occipital cortex (Di Russo et al., 2002). Since the reason for this difference lies in the anatomical construction of the visual system, it should hold also for the single trials. This means that the amplitude of the single-trial ERPs at the latency of the P1 should be more positive and the amplitude at the latency of the subsequent $\mathrm{N} 1$ should be more negative at the contralateral side of the brain. By subtracting the amplitude of P1 and $\mathrm{N} 1$ over the left hemisphere from that over the right hemisphere, we aimed at increasing signal-to-noise ratio of the ERP component of interest with respect to the background EEG. The resulting regressor composed of amplitude differences must predict, retrospectively, the right or left position of a stimulus on the screen. The procedure can be considered as a primitive mind-reading technique like the one existing on the basis of fMRI data alone (Dehaene et al., 1998). However, taking the ERP amplitude into account may allow to obtain more information about the sources of activity at certain time intervals after the stimulus onset.

In summary, we used the individual ERP peak amplitude to retrospectively predict the location of the stimulus and introduced this stimulus-blind information into the fMRI analysis. Two hypotheses were tested: (1) the ERP-informed visual fMRI will highlight a subset within the set of visual areas which are revealed by traditional fMRI and (2) there will be non-overlapping areas for P1 and N1 within the ERP-informed subset.

\section{Methods}

\section{Participants}

14 subjects participated in the study (10 males, age $21-33$ years, median 25 years, three left-handed). They reported no neurological diseases and had normal or corrected-to-normal vision. During the presentation of the stimuli subjects were lying supine in the scanner on a cushion that ameliorated the pressure from the EEG electrodes on the head. The head of the subject was restricted in the coil with soft cushions. Subjects were provided with earplugs to avoid harmful effect of fMRI acoustic noise.

\section{Stimuli and presentation}

The stimulation paradigm was generated and presented with the Presentation software (Neurobehavioral Systems, Albany, CA, USA). Quadrant segments of a circular checkerboard were projected from the technical room of the scanner to the plastic screen $(17 \times 25 \mathrm{~cm})$ positioned at the upper internal surface of the scanner bore (Fig. 1). The subject saw the screen reflection in the mirror positioned at the top of the head coil at a distance of $29 \mathrm{~cm}$ from the screen. The distance between the eyes and the mirror was $6 \mathrm{~cm}$. The segments were $6^{\circ}(3.4 \times 3.3 \mathrm{~cm})$ in size and their centers were positioned at $8^{\circ}$ $(5 \mathrm{~cm})$ distance from the fixation point. The spatial frequency of the stimuli was 0.5 cycles/degree. They were presented equiprobable with randomized stimulus-onset asynchronies (SOAs) to each of four quadrants: upper left (UL), upper right (UR), lower left (LL), and lower right (LR) (Fig. 1). The subject was instructed to fixate the cross in the middle of the screen and to press a button whenever (s)he detected a checkerboard. In addition, a full checkerboard with about $5^{\circ}$ radius was presented centrally with the same probability as each of the segment positions. The stimuli were presented in four blocks of 100 stimuli and 61 empty events each. Empty events provided a 
A

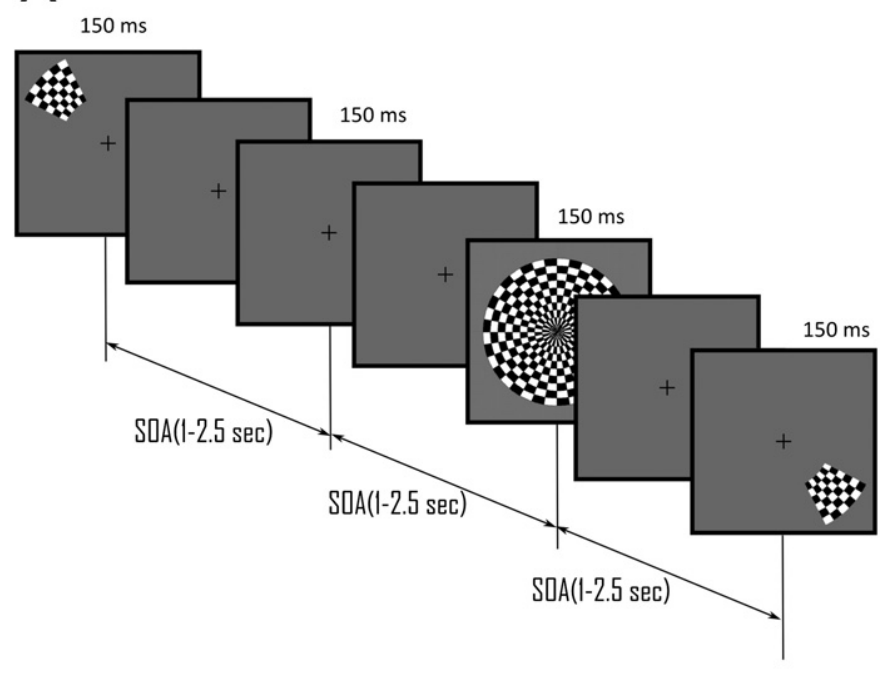

B
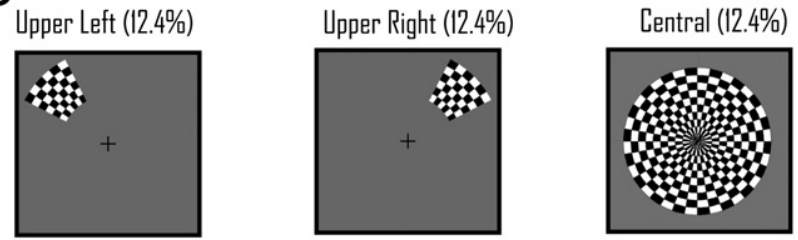

Lower Left (I2.4\%)
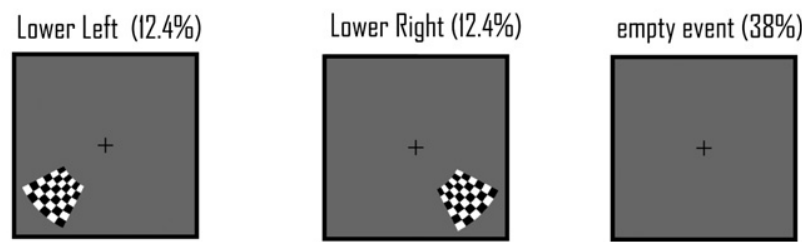

Fig. 1. Experimental paradigm. (A) Fragment of the stimulus sequence with an indication of the SOA-stimulus-onset-asynchrony. (B) Stimulus types, from the upper left to the lower right corner: upper left (UL), upper right (UR), central, lower left (LL), lower right (LR) and empty event.

baseline for the fMRI event-related analysis. The figure during empty events was not different from the inter-stimulus interval, i.e. a grey screen with a fixation cross (Fig. 1). The SOA varied randomly from 1 to $2.5 \mathrm{~s}$ in $100 \mathrm{~ms}$ steps. While SOAs of more than $2 \mathrm{~s}$ are usually recommended in event-related fMRI studies, adding empty events was shown to increase efficiency of a BOLD signal so that SOAs of less than $1.5 \mathrm{~s}$ can be used (Wager and Nichols, 2003). The design is thus getting closer to the ERP study designs where SOAs of $1 \mathrm{~s}$ and smaller are common. The instructions, the random order of the segment positions, the form of the segments, and the introduction of a central stimulus motivated the subject to keep central fixation. In the same session and intermingled with the present task (but in different blocks), the subject performed another task which is not considered in this paper.

\section{Simultaneous EEG and fMRI recording}

EEG was recorded with the Brain Amp + system hardware and the Brain Vision Recorder software (BrainProducts, Munich, Germany). EEG was recorded from the scalp at $5 \mathrm{kHz}$ digitization rate with a 64-
MRI compatible electrode cap, which was fed via short cables to the amplifiers inside the scanner room. $\mathrm{FCz}$ was used as reference electrode and the inion position (Iz electrode) was used as ground electrode. Two channels of the electrode cap were used to record monopolar elecrooculogram (EOG) and electrocardiogram (ECG) data; the corresponding electrodes were respectively attached under the left eye and above the left scapula of the subject. The impedance between electrode and scalp was kept below $10 \mathrm{k} \Omega$. The MRI compatible amplifiers were placed at the edge of the scanner bore and the wires that connected the cap with the amplifier were fixed in their position with sand bags to avoid vibrations. The digital output from the amplifiers was fed via optical cables into a dedicated laptop positioned outside the scanner.

fMRI data were recorded with a Philips 3T Intera whole-body scanner. 160 echo-planar images (EPI) composed of 28 slices of $3 \times 3 \times 4.5 \mathrm{~mm}$ voxel size and $4.8 \mathrm{~mm}$ slice thickness were recorded with ascending slice order with $1.95 \mathrm{~s}$ repetition time (TR) during each experimental block. For anatomical reference a full brain anatomical images were obtained with the magnetization prepared rapid gradient echo (MPRAGE) imaging sequence (230 coronal slices, time to echo $[\mathrm{TE}]=4.6 \mathrm{~ms}, \mathrm{TR}=9.7 \mathrm{~s})$.

\section{EEG preprocessing and analysis}

The EEG data were imported into MATLAB (The Mathworks Inc., Natick, Massachusetts, USA) and the analysis was done with the EEGLAB toolbox (Delorme and Makeig, 2004). EEG data were cleaned from gradient artifacts by a modified version of the template subtraction (Allen et al., 2000). Creating this template was not continuous along the whole data set, but was interrupted at the moment of subject motion as informed by the realignment parameters from the fMRI analysis, as realized in the Bergen EEG-fMRI EEGLAB plug-in (Moosmann et al., 2009). The data were subsequently down-sampled to $250 \mathrm{~Hz}$ and bandpass filtered between 1 and $30 \mathrm{~Hz}$. The ballistocardiogram (BCG) artifact was removed with template subtraction based on the optimal basis set (OBS) method from the EEGLAB FMRIB tool (Niazy et al., 2005). Residual BCG artifacts were removed with ICA. More specifically, components that explained more than $10 \%$ of the variance in the ECG channel were removed. The combination of OBS and ICA has been previously shown to yield the best results in BCG removal (Debener et al., 2007a), as long as precautions are taken not to remove too much of the activity (Vanderperren et al., 2010). The blink-related EEG activity was also removed with ICA. Blinks were detected on the EOG channel as a transient deflection in amplitude and the blink-related independent component was defined as the one that explained more than $10 \%$ of the variance at the EOG electrode in blink-locked epochs (Mennes et al., 2010). The data were segmented from $100 \mathrm{~ms}$ before until $400 \mathrm{~ms}$ after stimulus onset, artifact-rejected at $200 \mu \mathrm{V}$, baseline corrected $(-100$ to $0 \mathrm{~ms}$ ) and re-referenced to the average of TP9 and TP10 (the closest electrodes to the mastoids in the present electrode setup). ERPs were averaged separately for responses to the stimuli in each of four quadrants and the central stimulus. In addition, we created a so-called contra-ipsilateral voltage map. To that end, first, the responses to the upper and lower visual fields were averaged together and subsequently the responses to the right visual field (RVF) were flipped around the central line and averaged together with the responses to the left visual field (LVF). P1 was measured as a positive deflection in the $50-150 \mathrm{~ms}$ time window and $\mathrm{N} 1$ as a negative deflection in the $150-250 \mathrm{~ms}$ window at the occipital electrodes of contralateral hemisphere of the contra-ipsilateral voltage map. A set of five occipito-temporal electrodes

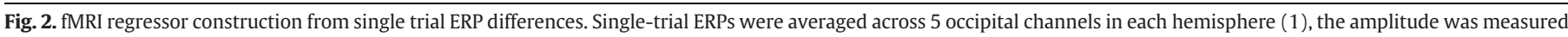

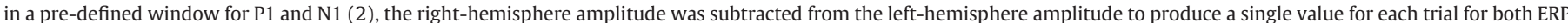

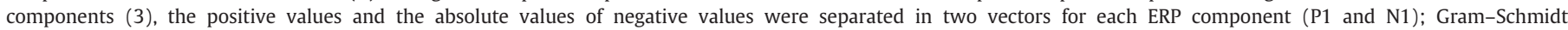

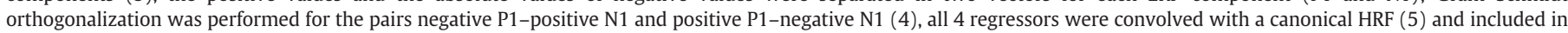
one general linear model (GLM) design (not shown). 
(1)

(2)
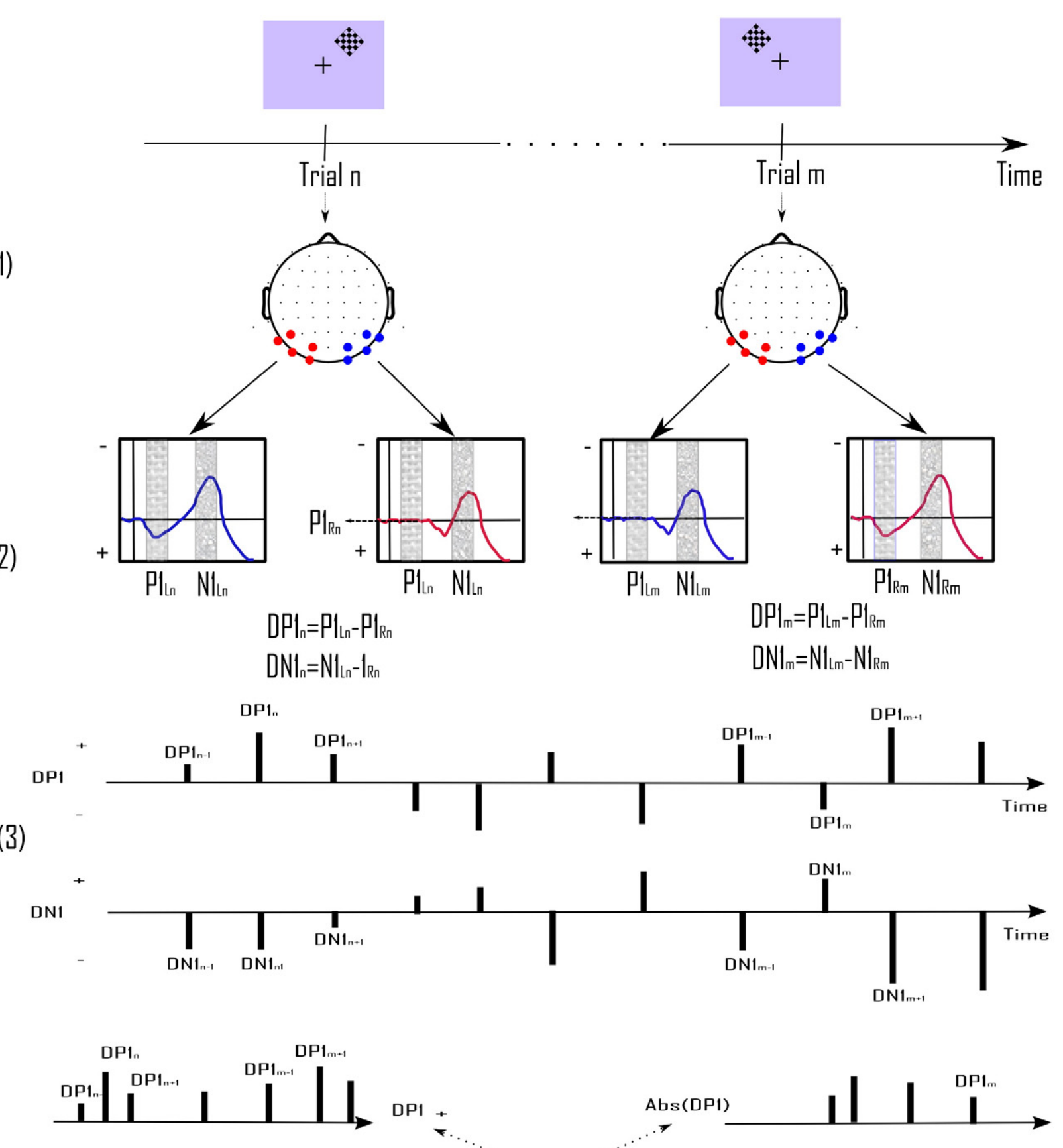

(4)
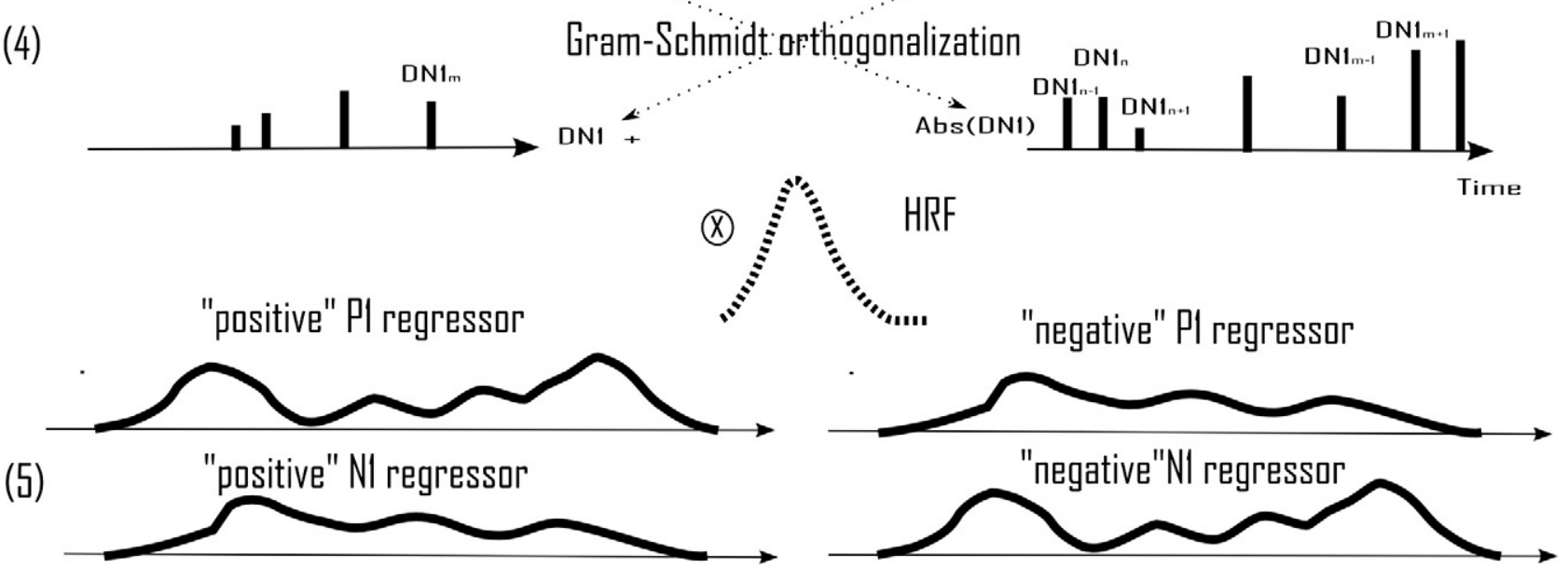


\section{CENTRAL STIMULUS}
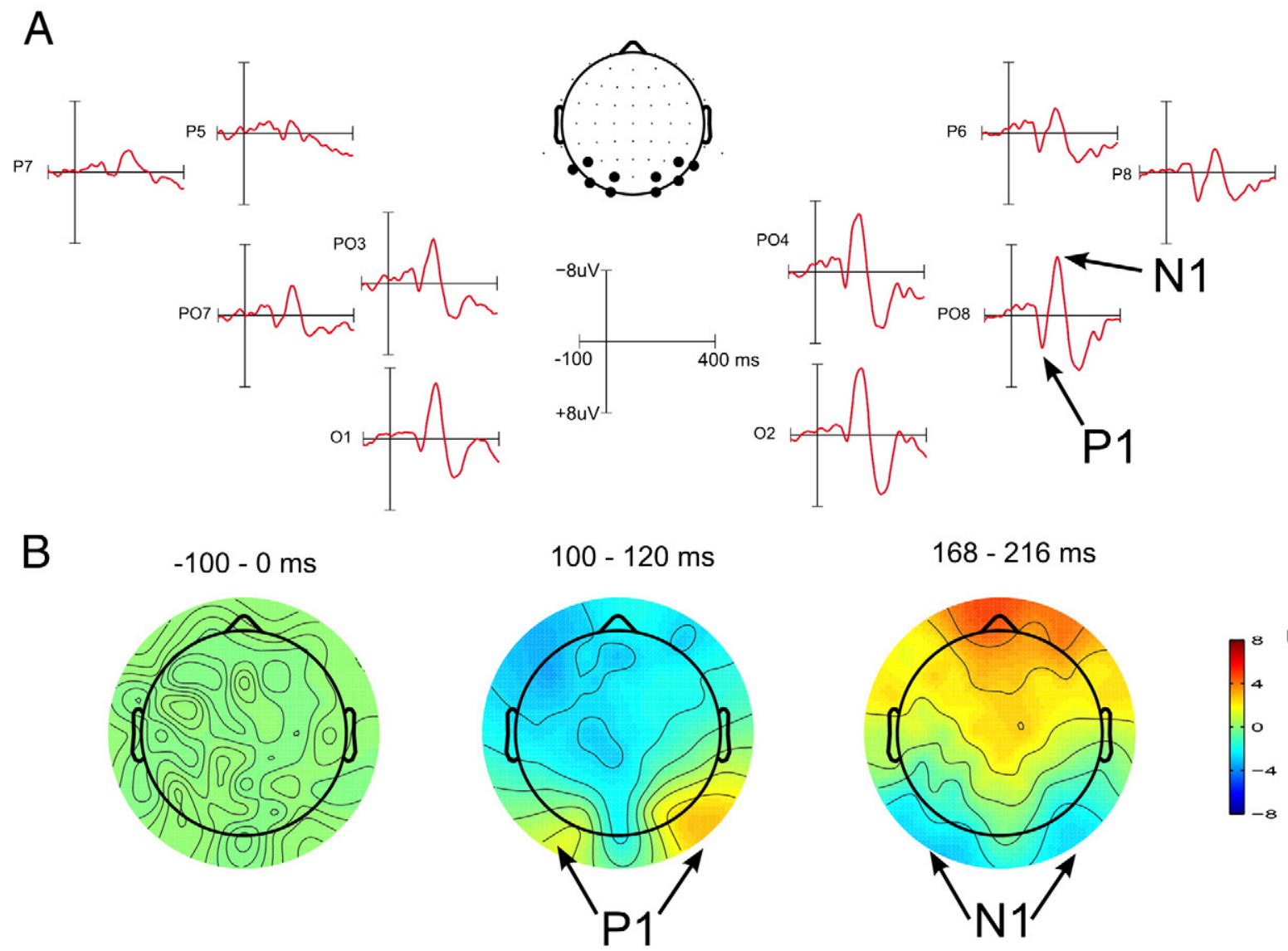

$168-216 m s$

\section{B}

C

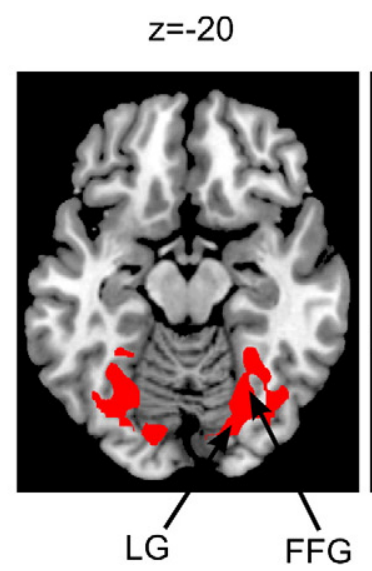
$z=-10$ $z=0$

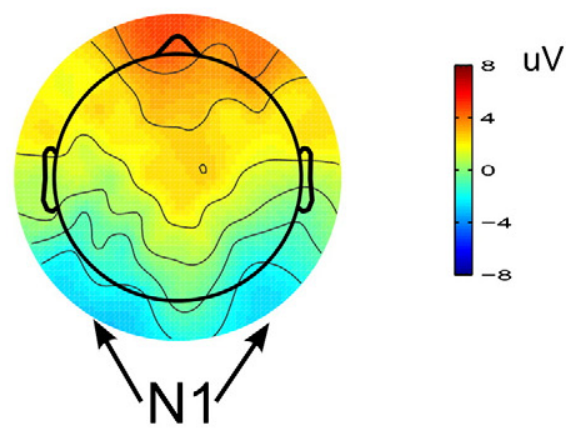
uV
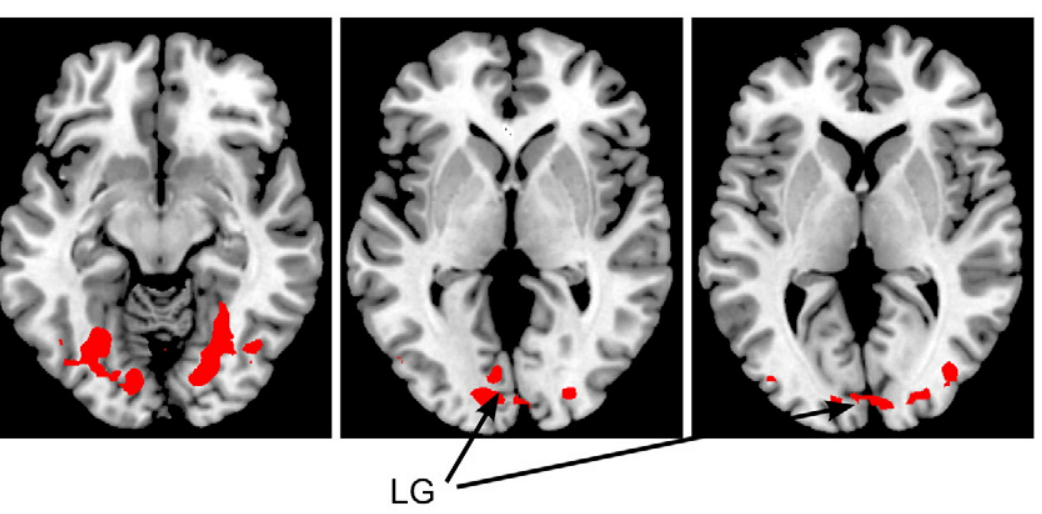

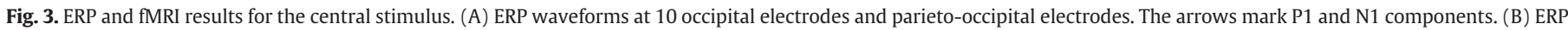

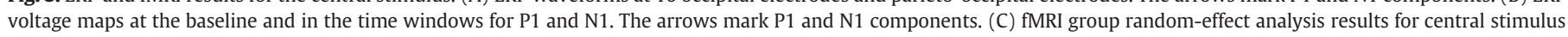
$(p<0.001$, uncorrected). FG-fusiform gyrus, LG-lingual gyrus.

in each of the left $(01, \mathrm{P} 7, \mathrm{PO} 3, \mathrm{P} 5, \mathrm{PO} 7)$ and right (O2, P8, PO4, P6, PO8) hemispheres was chosen to measure the amplitudes of the ERP, as P1 and N1 were best pronounced at those electrodes.

\section{fMRI preprocessing and analysis}

fMRI analysis was performed with the statistical parametric mapping software (SPM5, Wellcome Department of Cognitive Neurology, London, UK) in MATLAB. The EPI time-series were slice-time corrected, realigned, co-registered with anatomical images, normalized and smoothed with an 8-mm FWHM Gaussian kernel using SPM5.
Two types of event-locked regressors were used in the fMRI analysis: (1) a stick function at the onset of the stimulus as in traditional event-related fMRI and (2) the amplitude from the individual ERP sweep at the onset of the stimulus, resulting in a socalled integration-by-prediction analysis. The predictors were differences between the ERP amplitude of the right and left hemisphere at P1 and N1 latencies at the occipital electrodes.

In the stick-function analysis, first-order statistics were calculated on the basis of convolution of the stick function at the stimulus timing with a canonical HRF, separately for the 5 stimulus locations (UL, UR, LL, LR, CC). No derivatives were used in the analysis. The 6 


\section{LEFT VISUAL FIELD STIMULI}
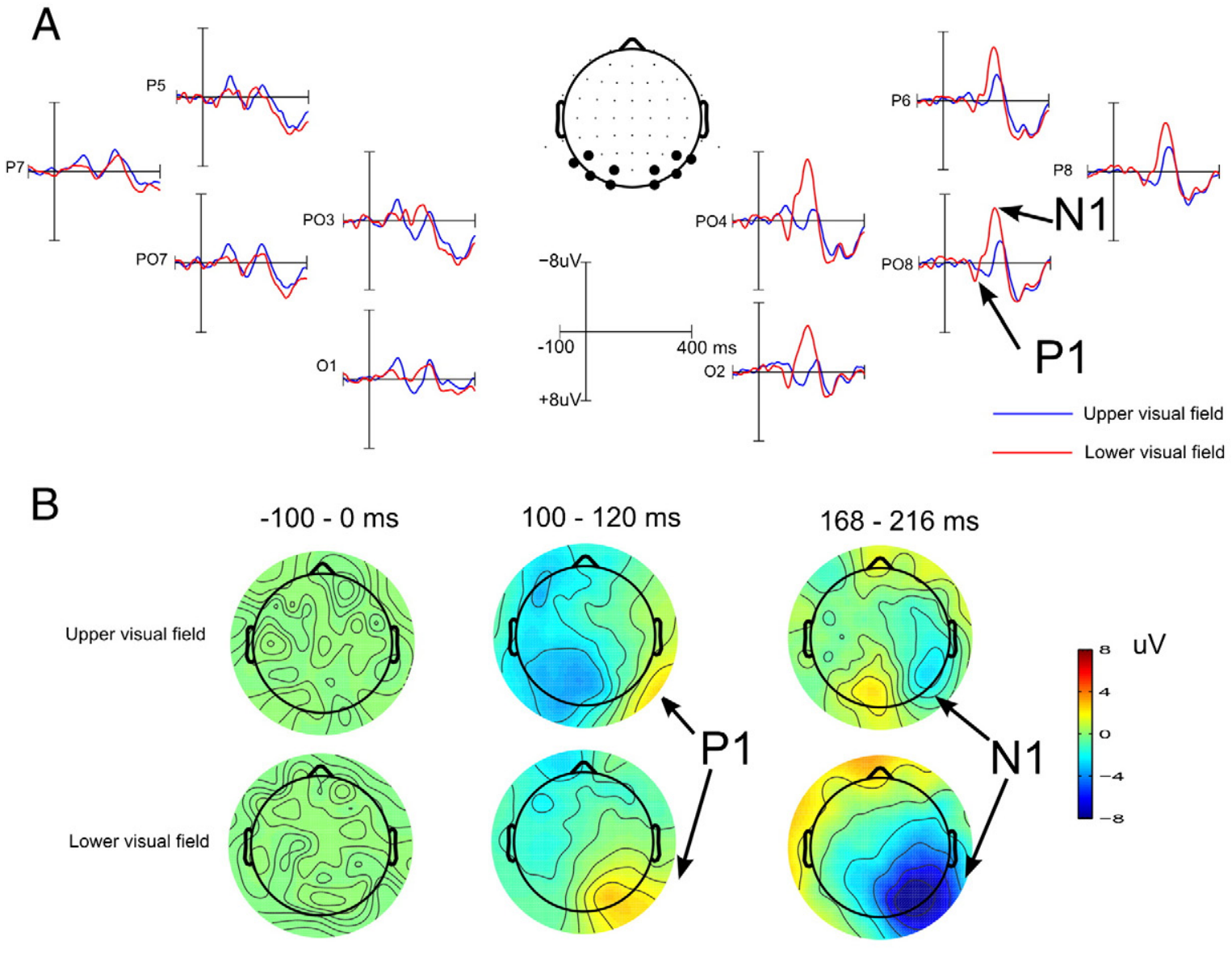

$168-216 \mathrm{~ms}$

C

$X=13$

$z=-10$

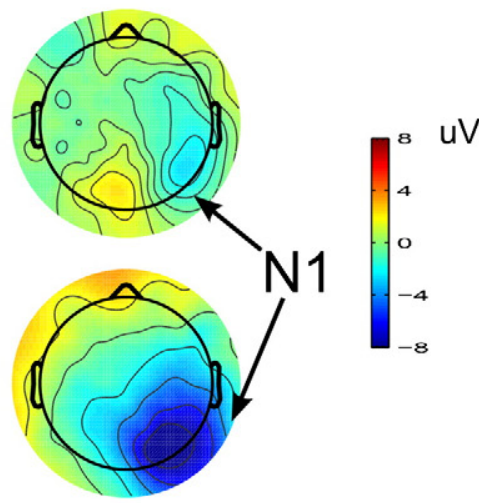

$z=0$

$z=10$

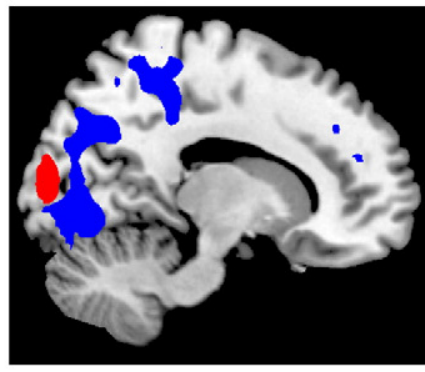

Upper visual field
Lower visual field
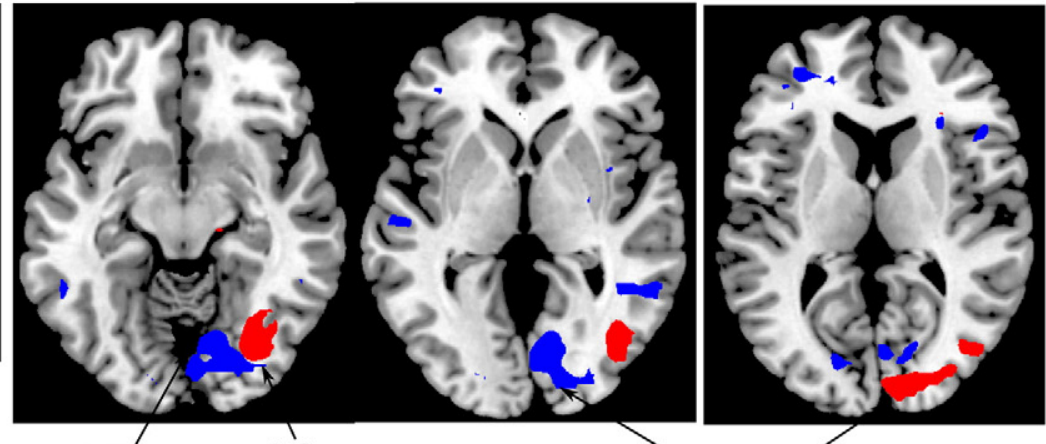

$\mathrm{FG}$

LG

LG

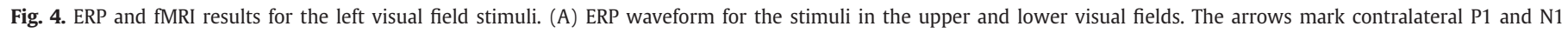

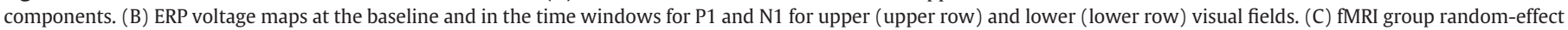
analysis results for contrast UL-(UR + LL + LR) and LL-(UR + UL + LR) $(p<0.001$, uncorrected). FG-fusiform gyrus, LG-lingual gyrus.

movement parameters (three for both translation and rotation) obtained during realignment were inserted in the model as covariates of no interest. As a result, the design consisted of $5+$ $6=11$ variables per experimental block per subject. In the analysis with second-order statistics (random-effect analysis), the contrasts of the five stimulus types and the baseline for each individual subject were used. We report the results of the contrast between each peripheral stimulus type and all other peripheral stimuli, as well as the contrast of the right and left visual field responses against the baseline.
For an ERP-amplitude informed analysis, the cleaned, segmented, baseline-corrected and re-referenced EEG data were used. The construction of the regressor is schematically shown at Fig. 2. The single-trial amplitudes in the individually measured time windows of P1 and $\mathrm{N} 1$ (individual peak latency $\pm 4 \mathrm{~ms}$ ) were measured and averaged across five occipital electrodes of each hemisphere for each individual trial (one per hemisphere).

The procedure of dealing with the artifact-contaminated trials was modified in the regressor construction as compared to the averaged ERP amplitude and latency measurement. Here, all 


\section{RIGHT VISUAL FIELD STIMULI}
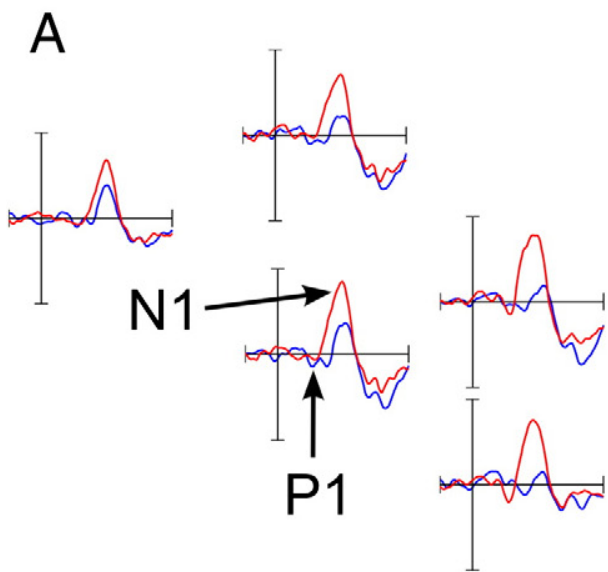

B

Upper visual field

Lower visual field

$-100-0 \mathrm{~ms}$
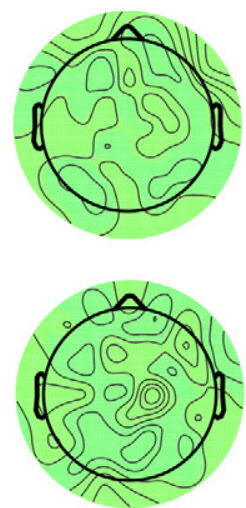

C $\quad x=-13$

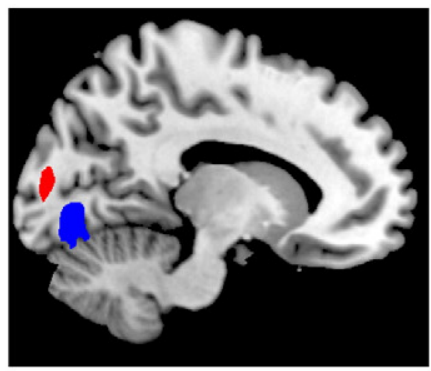

Upper visual field

Lower visual field
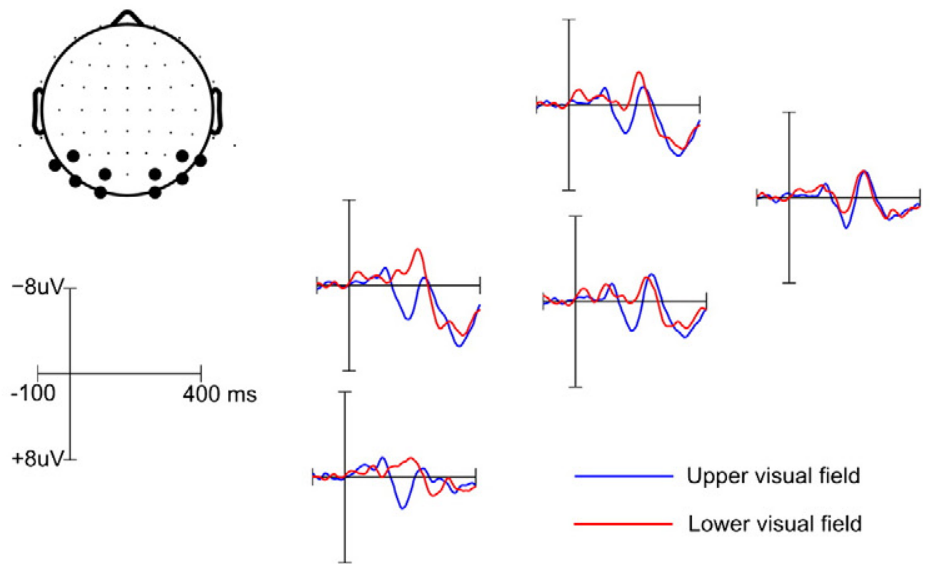

Lower visual field
$100-120 \mathrm{~ms}$
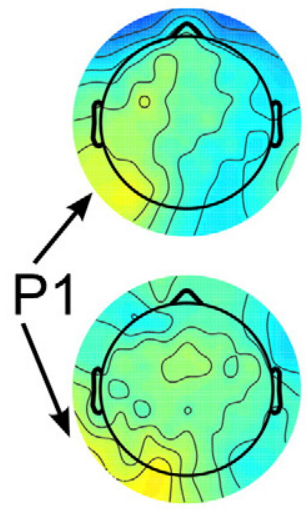

$z=-10$

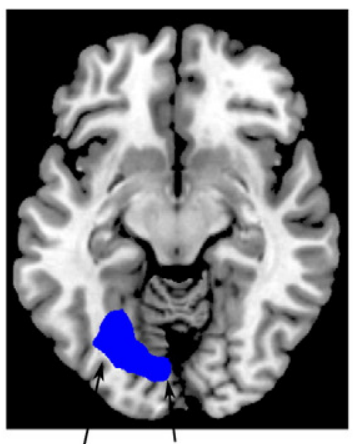

FG

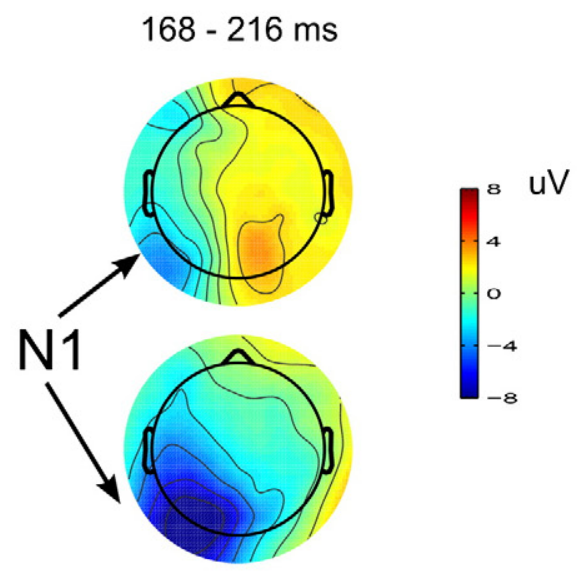

$\mathrm{z}=0$

$z=10$

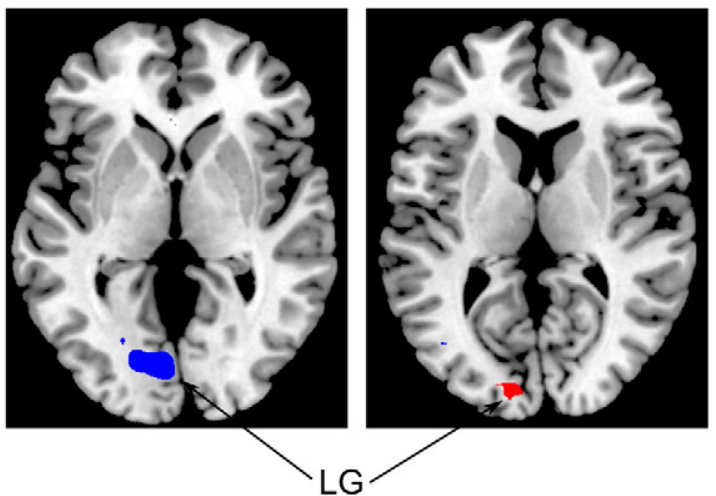

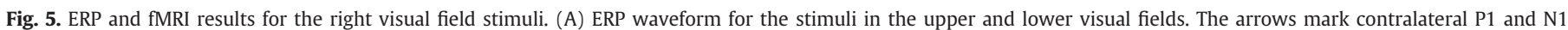

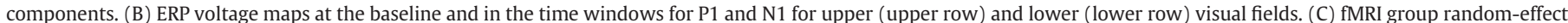
analysis results for contrast UR-(UL + LL + LR) and LR-(UR + UL + LL) ( $p<0.001$, uncorrected). FG-fusiform gyrus, LG-lingual gyrus.

amplitude values beyond $\pm 75 \mu \mathrm{V}$ or 3 standard deviations (whatever of two values was higher) from zero were substituted with the mean of the data within 3 standard deviations. That produced two values per component for each single trial. Then the single-trial amplitudes of the right hemisphere electrodes were subtracted from the single-trial amplitudes of the left hemisphere. Again, all difference values beyond 3 standard deviations or $\pm 75 \mu \mathrm{V}$ (whatever of two values was higher) from zero were substituted with the mean of the data within 3 standard deviations. The number of substituted trials at single electrodes at first padding was $5 \pm 0.1$ for both the P1 and N1; at the second padding it was $3 \pm 0.5$ for the P1 and $3 \pm 0.6$ for the N1 (out of 400 trials). We checked whether the resulting ERP regressor predicted the side of the stimulating visual field in each individual subject significantly higher than chance level with a single proportion significance test (Wilson, 1927). 
The resulting vectors of amplitude differences were split according to the polarity of the amplitude difference (for DP1, positive values corresponded to larger amplitude in the left hemisphere, whereas for DN1, negative values corresponded to larger amplitude in the left hemisphere). The negative numbers were then substituted with their absolute values. This resulted in two vectors per subject per block per ERP component: positive DP1, negative DP1, positive DN1 and negative DN1. The vectors were orthogonalized with the GramSchmidt method in the pairs positive DP1-negative DN1 and negative DP1-positive DN1 and normalized. Then the four vectors were convolved with the canonical HRF to create four regressors for the fMRI analysis. The movement parameters were used as covariates of no interest just as in the standard fMRI analysis. In the analysis with second-order statistics (random-effect analysis) a conjunction contrast of all of the four regressors against baseline was used (Fig. 2).

In all the group analyses the threshold was defined as $p<0.001$ uncorrected with minimal cluster size of 10 voxels. Brain structures were identified with Munster T2T converter (http://wwwneuro03. uni-muenster.de/ger/t2tconv/conv3d.html) by the MNI coordinates of the cluster.

\section{Results}

\section{ERP results}

The obtained ERPs were dominated by contra- and ipsilateral P1 and $\mathrm{N} 1$ components (Figs. 3-5A-B). The $\mathrm{C} 1$ component was less pronounced (but can be noticed on e.g. Fig. 4A, electrode PO4).

The contralateral P1 had an amplitude of $1.32 \pm 0.33 \mu \mathrm{V}$ and a latency of $119 \pm 6.2 \mathrm{~ms}$. The ipsilateral P1 had an amplitude of $1.09 \pm$ $0.35 \mu \mathrm{V}$ and a latency of $143 \pm 7.1 \mathrm{~ms}$. The latency of the contralateral P1 was significantly shorter than that of the ipsilateral P1 (t-test, $p<0.05)$. The contralateral $\mathrm{N} 1$ had an amplitude of $-4.36 \pm 0.56 \mu \mathrm{V}$ and a latency of $194 \pm 3.3 \mathrm{~ms}$. The ipsilateral N1 had an amplitude of $-1.98 \pm 0.58 \mu \mathrm{V}$ and a latency of $192 \pm 7.8 \mathrm{~ms}$. The amplitude of the contralateral N1 was significantly larger than that of the ipsilateral N1 (t-test, $p<0.05$ )

The location of the stimulus in the right-left direction corresponded to the sign of the difference between the left and right hemisphere electrodes in more than $50 \%$ of individual trials in most of the subjects for both P1 and N1, as shown by the t-test statistics over 14 subjects (Table 1 ). Out of 14 subjects, six showed significant prevalence of larger P1 amplitude in the right hemisphere with LVF

Table 1

The percentage of correct predictions of the laterality of the visual field by single-trial between-hemisphere ERP differences for each subject and their group average. Values significantly higher than $50 \%(p<0.05)$ are given in bold. Group differences between right and left hemisphere ( $t$-test with Bonferroni correction): ${ }^{*} p<0.05,{ }^{* * *} p<0.001$. LVF -left visual field; RVF-right visual field; LH-left hemisphere, $\mathrm{RH}-$ right hemisphere.

\begin{tabular}{|c|c|c|c|c|}
\hline Participants & $\begin{array}{l}\text { LVF predicted } \\
\text { by } \mathrm{P} 1 \text { in } \mathrm{RH}\end{array}$ & $\begin{array}{l}\text { RVF predicted } \\
\text { by } \mathrm{P} 1 \text { in } \mathrm{LH}\end{array}$ & $\begin{array}{l}\text { LVF predicted } \\
\text { by } \mathrm{N} 1 \text { in } \mathrm{RH}\end{array}$ & $\begin{array}{l}\text { RVF predicted } \\
\text { by } \mathrm{N} 1 \text { in } \mathrm{LH}\end{array}$ \\
\hline P1 & $53 \%$ & $46 \%$ & $60 \%$ & $55 \%$ \\
\hline P2 & $63 \%$ & $62 \%$ & $62 \%$ & $58 \%$ \\
\hline P3 & $51 \%$ & $53 \%$ & $53 \%$ & $59 \%$ \\
\hline P4 & $58 \%$ & $51 \%$ & $59 \%$ & $53 \%$ \\
\hline P5 & $65 \%$ & $66 \%$ & $78 \%$ & $64 \%$ \\
\hline P6 & $60 \%$ & $56 \%$ & $62 \%$ & $63 \%$ \\
\hline P7 & $59 \%$ & $58 \%$ & $68 \%$ & $80 \%$ \\
\hline P8 & $59 \%$ & $57 \%$ & $52 \%$ & $71 \%$ \\
\hline P9 & $53 \%$ & $54 \%$ & $69 \%$ & $58 \%$ \\
\hline P10 & $46 \%$ & $52 \%$ & $69 \%$ & $67 \%$ \\
\hline P11 & $56 \%$ & $54 \%$ & $69 \%$ & $57 \%$ \\
\hline P12 & $53 \%$ & $59 \%$ & $58 \%$ & $67 \%$ \\
\hline P13 & $46 \%$ & $42 \%$ & $58 \%$ & $65 \%$ \\
\hline P14 & $66 \%$ & $59 \%$ & $54 \%$ & $65 \%$ \\
\hline Mean & $56 \% \pm 1.7^{*}$ & $54 \% \pm 1.6^{*}$ & $62 \% \pm 2.0^{* * *}$ & $63 \% \pm 1.9^{* * *}$ \\
\hline
\end{tabular}

stimulation, four showed significant prevalence of larger P1 amplitude in the left hemisphere with RVF stimulation, nine showed significant prevalence of larger N1 amplitude in the right hemisphere with LVF stimulation and nine showed significant prevalence of larger N1 amplitude in the left hemisphere with RVF stimulation (Table 1).

\section{fMRI results}

Central stimuli activated bilateral areas in the fusiform gyri, lingual gyri, inferior and middle occipital gyri and some activation was found also in the right insula and left parahippocampal gyrus (Table 2, Fig. 3C).

The contrast "Lower Left-All other peripheral stimuli" revealed activations in the right middle occipital gyrus (Brodmann Area-BA 18) and the right cuneus (BA 7). The contrast "Upper Left-All other peripheral stimuli" revealed largest activations in the right lingual gyrus (BA 18), left superior parietal lobule (BA 7), and right inferior frontal gyrus (BA 45). In addition, a set of minor activations was revealed in the right anterior cingulate, left inferior frontal gyrus, bilateral inferior parietal lobe, bilateral insula, right medial frontal gyrus, right middle temporal gyrus, left postcentral gyrus, left precentral gyrus, left precuneus, left posterior cingulate, bilateral superior frontal gyrus, left superior parietal lobule bilateral superior temporal gyrus, right supramarginal gyrus, and right claustrum (Table 2, Fig. 4C).

The contrast "Lower Right-All other peripheral stimuli" revealed activations in the left middle occipital gyrus (BA 18 and 19). The contrast "Upper Right-All other peripheral stimuli" revealed activations in the left lingual gyrus (BA 18), left superior occipital gyrus (BA 19), and left middle temporal gyrus (BA 37) (Table 2, Fig. 5C).

The contrast "LVF-RVF" revealed activations in the right lingual gyrus (BA 18), right middle occipital gyrus (BA 18), right inferior frontal gyrus (BA 45), right paracentral lobule (BA 5), and right middle frontal gyrus (BA 9). The contrast "RVF-LVF" revealed activations in the left lingual gyrus (BA18) (Table 2, Fig. 6A).

\section{ERP-informed-fMRI results}

DP1pos correlated with left middle occipital gyrus (BA 37), left middle temporal gyrus (BA 19), left fusiform gyrus (BA 19 and 37), as well as with the left inferior parietal lobule, left medial frontal gyrus, left postcentral gyrus, left precentral gyrus, thalamus, brainstem, and bilateral cerebellum. DP1neg correlated with the right middle occipital gyrus (BA 37), left medial frontal gyrus (BA 6), and left precentral gyrus (BA 4) (Table 3, Fig. 6B).

DN1neg latency correlated with the left middle temporal gyrus (BA 39), left medial frontal gyrus (BA 6), left precentral gyrus (BA 4), as well as with thalamus and brainstem. Positive values of the amplitude difference between the left and right hemispheres at DN1pos latency correlated with the right middle temporal gyrus (BA 39), left medial frontal gyrus (BA 6), and left precentral gyrus (BA 6 and 4) (Table 3, Fig. 6C).

\section{Discussion}

We proposed a new modification of the integration-by-prediction approach for simultaneous EEG-fMRI studies. In this study, the regressor is constructed from the differences between the individual-trial amplitudes of the left and right hemisphere electrodes subsets. The method has been validated in a simple spatial detection visual paradigm with checkerboard stimuli presented in four quadrants of the visual field. The quality of the ERPs recorded inside the scanner allowed to discriminate the P1 and N1 components. To our knowledge this study is the first that produced visual ERP to peripheral stimuli inside the scanner in parallel with continuous fMRI acquisition. While the traditional stick-function event-related fMRI analysis revealed activations mostly in the primary visual areas and in the ventral 
Table 2

Event-related fMRI activations (random effect analysis, $p<0.001$ uncorrected, cluster size $>10$ ). The results for different contrasts are separate with contrast definitions in italic CC-central stimulus, UL-upper left quadrant, UR-upper right quadrant, LLlower left quadrant, LR-lower right quadrant.

\begin{tabular}{|c|c|c|c|c|c|c|c|}
\hline \multirow[t]{2}{*}{ Brain region } & \multirow{2}{*}{$\begin{array}{l}\text { Brodmann } \\
\text { area }\end{array}$} & \multirow[t]{2}{*}{ Hemisphere } & \multicolumn{3}{|c|}{ MNI coordinates } & \multirow{2}{*}{$\begin{array}{l}T \\
\text { value }\end{array}$} & \multirow{2}{*}{$\begin{array}{l}\text { Cluster } \\
\text { size }\end{array}$} \\
\hline & & & $X$ & $Y$ & $Z$ & & \\
\hline \multicolumn{8}{|l|}{$C C$} \\
\hline \multirow{2}{*}{ Fusiform gyrus } & 37 & $\mathrm{~L}$ & -37 & 58 & -20 & 10.89 & 848 \\
\hline & 37 & $\mathrm{~L}$ & -32 & -44 & -16 & 4.97 & 21 \\
\hline $\begin{array}{l}\text { Inferior occipital } \\
\text { gyrus }\end{array}$ & 18 & $\mathrm{~L}$ & -34 & -86 & 20 & 5.08 & 35 \\
\hline Insula & 13 & $\mathrm{R}$ & 58 & -34 & 18 & 5.62 & 21 \\
\hline Lingual gyrus & 18 & $\mathrm{R}$ & 20 & -78 & -14 & 7.32 & 885 \\
\hline $\begin{array}{l}\text { Middle occipital } \\
\text { gyrus }\end{array}$ & 18 & $\mathrm{R}$ & 38 & -82 & 2 & 5.28 & 56 \\
\hline $\begin{array}{l}\text { Parahippocampal } \\
\text { gyrus }\end{array}$ & $\mathrm{N} / \mathrm{A}$ & $\mathrm{L}$ & -31 & -11 & -21 & 5.55 & 13 \\
\hline \multicolumn{8}{|l|}{$U L-(U R+L R+L L)$} \\
\hline Anterior cingulate & 22 & $\mathrm{R}$ & 21 & 33 & 24 & 3.75 & 15 \\
\hline Claustrum & $\mathrm{N} / \mathrm{A}$ & $\mathrm{R}$ & 27 & 21 & 10 & 4.01 & 32 \\
\hline \multirow{2}{*}{$\begin{array}{l}\text { Inferior frontal } \\
\text { gyrus }\end{array}$} & 45 & $\mathrm{R}$ & 56 & 24 & 20 & 5.04 & 165 \\
\hline & 45 & $\mathrm{~L}$ & -52 & 23 & 24 & 3.74 & 13 \\
\hline \multirow{4}{*}{$\begin{array}{l}\text { Inferior parietal } \\
\text { lobule }\end{array}$} & 40 & $\mathrm{~L}$ & -54 & -38 & 38 & 4.42 & 48 \\
\hline & 40 & $\mathrm{R}$ & 52 & -48 & 46 & 4.09 & 99 \\
\hline & 40 & $\mathrm{R}$ & 58 & -34 & 40 & 3.87 & 18 \\
\hline & 7 & $\mathrm{R}$ & 38 & -66 & 44 & 3.86 & 22 \\
\hline \multirow[t]{3}{*}{ Insula } & 13 & $\mathrm{~L}$ & -39 & -44 & 18 & 4.71 & 38 \\
\hline & 13 & $\mathrm{~L}$ & -28 & -29 & 18 & 4.11 & 16 \\
\hline & 13 & $\mathrm{R}$ & 42 & -20 & 14 & 3.95 & 13 \\
\hline \multirow[t]{2}{*}{ Lingual gyrus } & 18 & $\mathrm{R}$ & 21 & -79 & -8 & 6.56 & 1601 \\
\hline & 18 & $\mathrm{~L}$ & -18 & -88 & -6 & 5.02 & 29 \\
\hline $\begin{array}{l}\text { Medial frontal } \\
\text { gyrus }\end{array}$ & 9 & $\mathrm{R}$ & 15 & 35 & 32 & 3.91 & 16 \\
\hline $\begin{array}{l}\text { Middle temporal } \\
\text { gyrus }\end{array}$ & 21 & $\mathrm{R}$ & 60 & -44 & -2 & 4.64 & 95 \\
\hline \multirow[t]{2}{*}{ Postcentral gyrus } & 3 & $\mathrm{~L}$ & -37 & -24 & 38 & 4.11 & 19 \\
\hline & 43 & $\mathrm{~L}$ & -58 & -6 & 16 & 3.73 & 11 \\
\hline $\begin{array}{l}\text { Posterior } \\
\text { cyngulate }\end{array}$ & 23 & & -4 & 38 & 22 & 4.02 & 27 \\
\hline Precentral gyrus & 6 & $\mathrm{~L}$ & -12 & -20 & 67 & 3.83 & 27 \\
\hline \multirow[t]{2}{*}{ Precuneus } & 31 & $\mathrm{~L}$ & -15 & -65 & 28 & 4.66 & 301 \\
\hline & 31 & $\mathrm{~L}$ & -17 & 46 & 32 & 4.62 & 58 \\
\hline \multirow{2}{*}{$\begin{array}{l}\text { Superior frontal } \\
\text { gyrus }\end{array}$} & 10 & $\mathrm{~L}$ & -32 & 50 & 28 & 6.11 & 906 \\
\hline & 10 & $\mathrm{R}$ & 26 & 47 & 22 & 5.37 & 296 \\
\hline $\begin{array}{l}\text { Superior parietal } \\
\text { lobule }\end{array}$ & 7 & $\mathrm{~L}$ & -17 & -50 & 64 & 6.47 & 1718 \\
\hline \multirow{3}{*}{$\begin{array}{l}\text { Superior Temporal } \\
\text { gyrus }\end{array}$} & 22 & $\mathrm{~L}$ & -56 & -20 & 0 & 4.70 & 58 \\
\hline & 22 & $\mathrm{~L}$ & -56 & -48 & -8 & 4.57 & 69 \\
\hline & 39 & $\mathrm{R}$ & 36 & -60 & 28 & 4.30 & 23 \\
\hline $\begin{array}{l}\text { Supramarginal } \\
\text { Gyrus }\end{array}$ & 40 & $\mathrm{R}$ & 63 & -43 & 30 & 4.08 & 18 \\
\hline \multicolumn{8}{|l|}{$U R-(U L+L R+L L)$} \\
\hline Lingual gyrus & 18 & $\mathrm{~L}$ & -20 & -76 & -10 & 7.59 & 1216 \\
\hline $\begin{array}{l}\text { Superior occipital } \\
\text { gyrus }\end{array}$ & 19 & $\mathrm{~L}$ & -28 & -84 & 24 & 5.53 & 151 \\
\hline $\begin{array}{l}\text { Middle temporal } \\
\text { gyrus }\end{array}$ & 37 & $\mathrm{~L}$ & -42 & -66 & 6 & 3.90 & 37 \\
\hline \multicolumn{8}{|l|}{$L L-(U L+U R+L R)$} \\
\hline $\begin{array}{l}\text { Middle Occipital } \\
\text { Gyrus }\end{array}$ & 18 & $\mathrm{R}$ & 12 & -92 & 14 & 8.65 & 1076 \\
\hline Cuneus & 7 & $\mathrm{R}$ & 23 & -82 & 29 & 4.09 & 13 \\
\hline \multicolumn{8}{|l|}{$L R-(U L+U R+L R)$} \\
\hline Middle occipital & 18 & $\mathrm{~L}$ & -14 & -92 & 12 & 6.97 & 76 \\
\hline $5 y+4$ & 19 & $\mathrm{~L}$ & -40 & -78 & 2 & 3.52 & 11 \\
\hline$(U L+L L)-(U R+L R)$ & & & & & & & \\
\hline $\begin{array}{l}\text { Middle occipital } \\
\text { gyrus }\end{array}$ & 18 & $\mathrm{R}$ & 12 & -92 & 14 & 6.68 & 369 \\
\hline
\end{tabular}

\begin{tabular}{|c|c|c|c|c|c|c|c|}
\hline \multirow[t]{2}{*}{ Brain region } & \multirow{2}{*}{$\begin{array}{l}\text { Brodmann } \\
\text { area }\end{array}$} & \multirow[t]{2}{*}{ Hemisphere } & \multicolumn{3}{|c|}{ MNI coordinates } & \multirow{2}{*}{$\begin{array}{l}T \\
\text { value }\end{array}$} & \multirow{2}{*}{$\begin{array}{l}\text { Cluster } \\
\text { size }\end{array}$} \\
\hline & & & $X$ & $Y$ & $Z$ & & \\
\hline \multicolumn{8}{|l|}{$(U L+L L)-(U R+L R)$} \\
\hline Lingual gyrus & 18 & $\mathrm{R}$ & 26 & -74 & -12 & 5.52 & 305 \\
\hline $\begin{array}{l}\text { Inferior frontal } \\
\text { gyrus }\end{array}$ & 45 & $\mathrm{R}$ & 32 & 26 & 6 & 4.82 & 43 \\
\hline Paracentral Lobule & 5 & $\mathrm{R}$ & 10 & -36 & 50 & 3.93 & 32 \\
\hline $\begin{array}{l}\text { Middle Frontal } \\
\text { Gyrus }\end{array}$ & 9 & $\mathrm{R}$ & 50 & 20 & 32 & 3.58 & 10 \\
\hline \multicolumn{8}{|l|}{$(U R+L R)-(U L+L L)$} \\
\hline \multirow[t]{2}{*}{ Lingual gyrus } & 18 & $\mathrm{~L}$ & -28 & -72 & -12 & 6.37 & 985 \\
\hline & 18 & $\mathrm{~L}$ & -8 & -78 & -2 & 3.93 & 48 \\
\hline
\end{tabular}

stream, the ERP-informed analysis gave more weight to the dorsal stream areas at the temporo-occipital junction. P1 and N1 were correlated with the same areas in the ERP-informed fMRI analysis.

In ERP-informed fMRI analysis, P1 and N1 amplitude regressors produced activations in the contralateral temporo-parietal junction within the dorsal visual stream at a substantial distance from the primary visual cortex (Fig. 6B-C). This corroborates previous data from separate EEG and fMRI sessions that the P1 and the N1 are generated in the extrastriate dorsal stream area (Di Russo et al., 2003, 2002). In addition, the left medial frontal and precentral gyri were activated, which probably reflects the motor-response activity, since most of our subjects were right-handed. The contralateral position of the activation in relation to the stimuli proves that the aim of the regressor to blindly catch the side of activation on the basis of the ERP amplitude is fulfilled. The stick-function fMRI analysis (Fig. 6A) for the LVF-RVF and RVF-LVF contrasts showed more activations in the ventral visual stream and in the vicinity of the primary visual areas. One may conclude that $\mathrm{P} 1$ and $\mathrm{N} 1$ individual trial modulations reflect upstream analysis in the dorsal visual stream. Given that the dorsal visual stream is normally associated with "where" processing (Creem and Proffitt, 2001; Haxby et al., 1991; Mishkin et al., 1983), its activation in a spatial detection task seems plausible.

Interestingly, the location of the activations for both P1 and N1 regressors (on average, $x= \pm 46, y=75, z=5$ ) is close to the one given for the area hMT+ (e.g., Sunaert et al., 1999). This is in agreement with the finding of MT activation in some studies that used peripheral visual stimuli at different locations (Di Russo et al., 2005; Liu et al., 2009). It may indicate the role of MT beyond its traditional function of motion area. Yet, without precise mapping of the areas with localizers, these conjectures remain speculations. The center of the MT-like cluster for P1 and N1 happens to fall into different anatomical and Brodmann areas (middle occipital gyrus, BA 37 for P1 and middle temporal gyrus, BA 39 for N1). However, the Euclidian distances between those clusters remain within the size of spatial smoothing and thus our hypothesis of spatial dissociation between P1 and N1 does not find confirmation at this level.

We retrieved retinotopic activations in our standard stick-function event-related fMRI analysis. When subtracted from the other peripheral stimuli responses, the quadrant stimuli mostly activated the occipital cortex in the contralateral position and inverted along the vertical coordinate, e.g. upper right stimulus produced lower left activation (Wandell et al., 2007). The activation for peripheral stimuli is not maximal in V1 at the banks of calcarine sulcus (BA 17). Instead, other occipital areas are activated, such as the lingual gyri and fusiform gyri (BA 18 and 19). Correspondingly, the ERP component C1, which is known to be generated in V1 (Di Russo et al., 2003, 2002, 2005) was not well pronounced. Several reasons may underlie this phenomenon. First, we used an active task, which necessarily involved involuntary attention allocation to every stimulus. Attention modulates extrastriate areas more than primary visual cortex (Di Russo et al., 2003). Second, the spatial frequency in our study was low, 0.5 cycles per degree in comparison with 4 cycles per degree in the study 


\section{RVF and LVF}

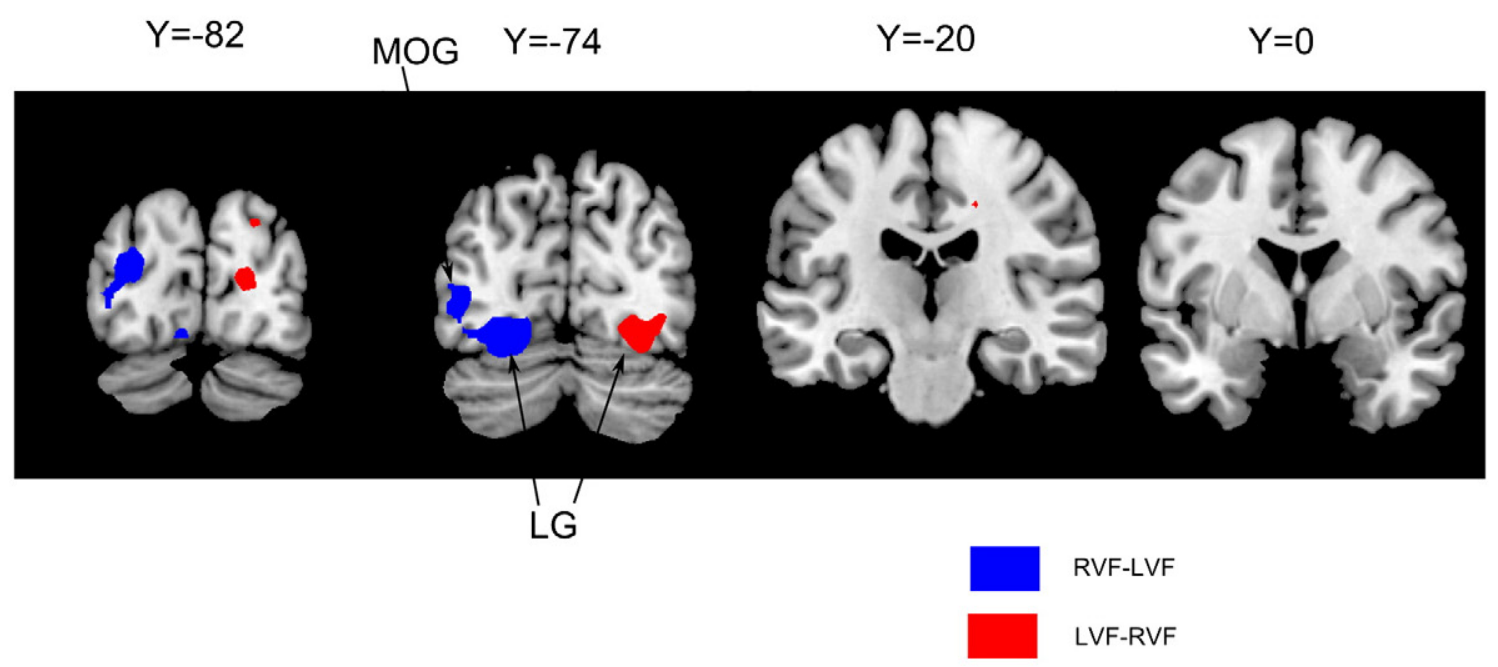

\section{$\mathrm{P} 1$}

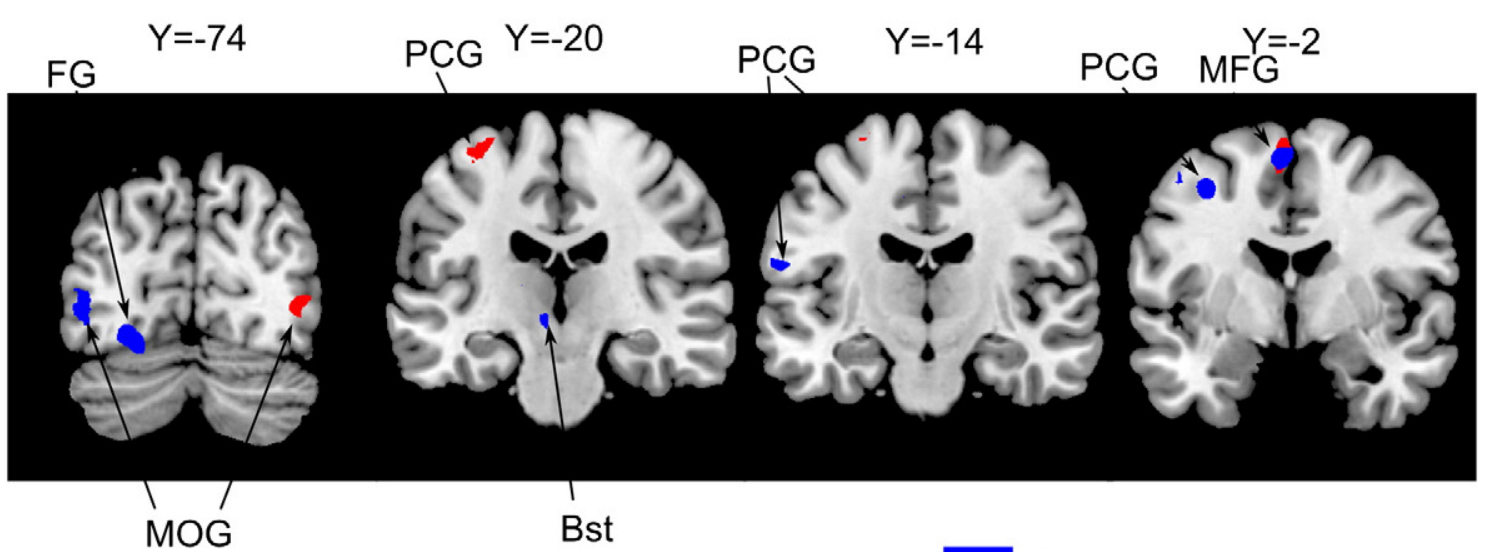

$\mathrm{P} 1$, positive regressor

$\mathrm{P} 1$, negative regressor

$\mathrm{N} 1$

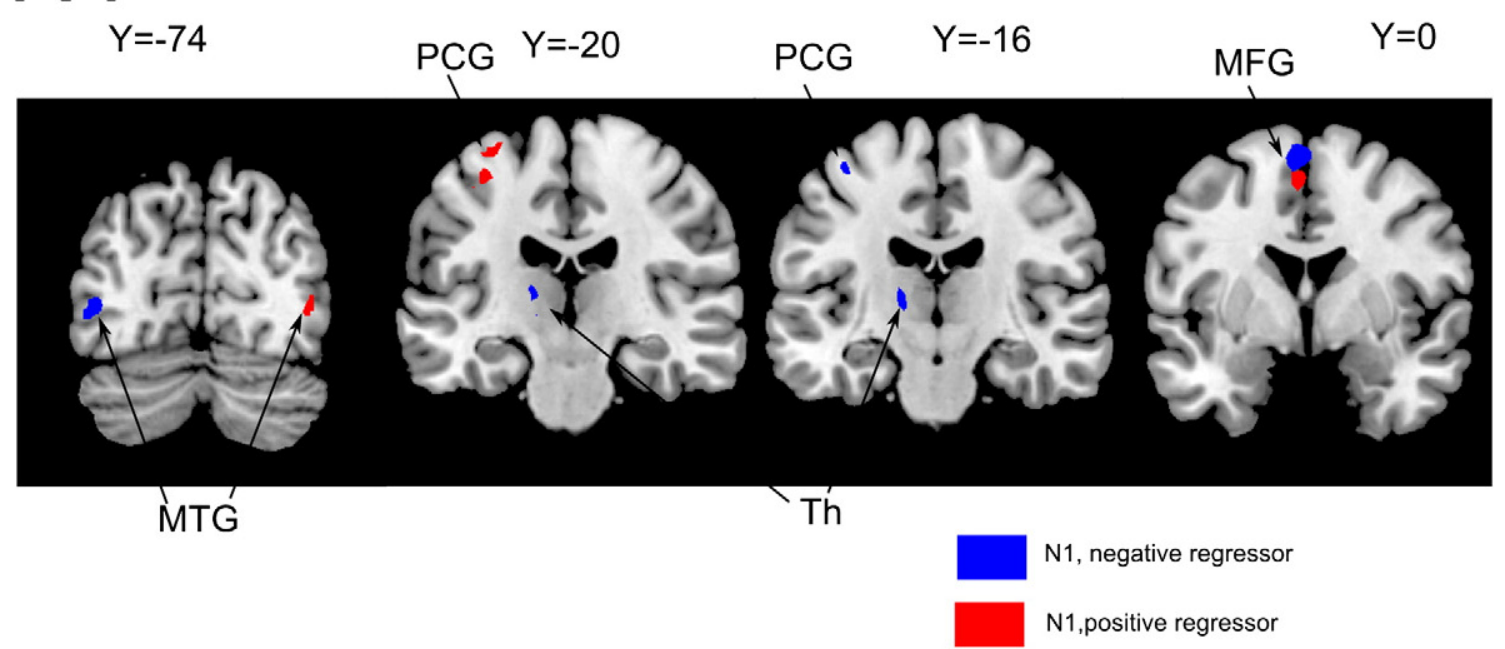

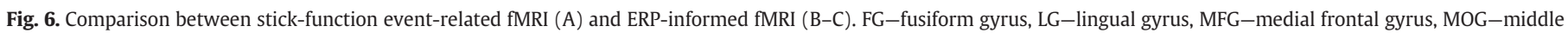
occipital gyrus, MTG-middle temporal gyrus, PCG-postcentral gyrus, Th-thalamus, BsT-brainstem. 
Table 3

ERP-informed fMRI activations (random effect analysis, $p<0.001$ uncorrected, cluster size $>10$ ). The results for different contrasts are separate with contrast definitions in italic.

\begin{tabular}{|c|c|c|c|c|c|c|c|}
\hline \multirow[t]{2}{*}{ Brain region } & \multirow{2}{*}{$\begin{array}{l}\text { Brodmann } \\
\text { area }\end{array}$} & \multirow[t]{2}{*}{ Hemisphere } & \multicolumn{3}{|c|}{ MNI coordinates } & \multirow{2}{*}{$\begin{array}{l}\mathrm{T} \\
\text { value }\end{array}$} & \multirow{2}{*}{$\begin{array}{l}\text { Cluster } \\
\text { size }\end{array}$} \\
\hline & & & $X$ & $Y$ & $Z$ & & \\
\hline \multicolumn{8}{|l|}{ N1 positive } \\
\hline $\begin{array}{l}\text { Medial frontal } \\
\text { gyrus }\end{array}$ & 6 & $\mathrm{~L}$ & -4 & -2 & 54 & 4.21 & 78 \\
\hline $\begin{array}{l}\text { Middle temporal } \\
\text { gyrus }\end{array}$ & 39 & $\mathrm{R}$ & 48 & -77 & 10 & 3.77 & 19 \\
\hline \multirow[t]{2}{*}{ Precentral gyrus } & 6 & $\mathrm{~L}$ & -32 & -20 & 68 & 4.14 & 23 \\
\hline & 4 & $\mathrm{~L}$ & -36 & -20 & 56 & 3.56 & 10 \\
\hline \multicolumn{8}{|l|}{ N1 negative } \\
\hline $\begin{array}{l}\text { Medial frontal } \\
\text { gyrus }\end{array}$ & 6 & $\mathrm{~L}$ & -4 & 0 & 64 & 4.8 & 78 \\
\hline $\begin{array}{l}\text { Middle temporal } \\
\text { gyrus }\end{array}$ & 39 & $\mathrm{~L}$ & -46 & -78 & 7 & 4.8 & 45 \\
\hline Precentral gyrus & 4 & $\mathrm{~L}$ & -38 & -16 & 58 & 3.66 & 11 \\
\hline Thalamus & $\mathrm{N} / \mathrm{A}$ & $\mathrm{L}$ & -16 & -18 & 4 & 3.92 & 23 \\
\hline Brainstem & $\mathrm{N} / \mathrm{A}$ & $\mathrm{N} / \mathrm{A}$ & -10 & -26 & -4 & 3.64 & 10 \\
\hline \multicolumn{8}{|l|}{ P1 positive } \\
\hline \multirow[t]{2}{*}{ Fusiform gyrus } & 19 & $\mathrm{~L}$ & -28 & -68 & -14 & 4.69 & 178 \\
\hline & 37 & $\mathrm{~L}$ & -26 & -50 & -14 & 3.91 & 28 \\
\hline $\begin{array}{l}\text { Inferior parietal } \\
\text { lobule }\end{array}$ & 40 & $\mathrm{~L}$ & -50 & -30 & 26 & 3.68 & 10 \\
\hline \multirow{2}{*}{$\begin{array}{l}\text { Medial frontal } \\
\text { gyrus }\end{array}$} & 6 & $\mathrm{~L}$ & -4 & -2 & 62 & 4.95 & 73 \\
\hline & 6 & $\mathrm{~L}$ & -38 & -3 & 48 & 4.44 & 34 \\
\hline $\begin{array}{l}\text { Middle occipital } \\
\text { gyrus }\end{array}$ & 37 & & -48 & 74 & 2 & 5.14 & 177 \\
\hline $\begin{array}{l}\text { Middle temporal } \\
\text { gyrus }\end{array}$ & 19 & $\mathrm{~L}$ & -30 & -84 & 16 & 3.7 & 13 \\
\hline Postcentral gyrus & 43 & $\mathrm{~L}$ & -60 & -14 & 18 & 3.6 & 10 \\
\hline Precentral gyrus & 6 & $\mathrm{~L}$ & -46 & -2 & 54 & 3.64 & 10 \\
\hline Thalamus & $\mathrm{N} / \mathrm{A}$ & $\mathrm{L}$ & -16 & -18 & 10 & 3.76 & 10 \\
\hline Brainstem & $\mathrm{N} / \mathrm{A}$ & $\mathrm{L}$ & -8 & -22 & -4 & 3.84 & 17 \\
\hline Cerebellum & $\mathrm{N} / \mathrm{A}$ & $\mathrm{L}$ & 0 & -68 & -14 & 3.87 & 11 \\
\hline Cerebellum & $\mathrm{N} / \mathrm{A}$ & $\mathrm{R}$ & 6 & -56 & -14 & 3.68 & 26 \\
\hline \multicolumn{8}{|l|}{ P1 negative } \\
\hline $\begin{array}{l}\text { Medial frontal } \\
\text { gyrus }\end{array}$ & 6 & $\mathrm{~L}$ & -4 & -2 & 62 & 4.49 & 61 \\
\hline Precentral gyrus & 4 & $\mathrm{~L}$ & -32 & -20 & 68 & 4.43 & 59 \\
\hline $\begin{array}{l}\text { Middle occipital } \\
\text { gyrus }\end{array}$ & 37 & $\mathrm{R}$ & 44 & -72 & 2 & 4.37 & 50 \\
\hline
\end{tabular}

of Di Russo (Di Russo et al., 2002). In future work it would be interesting to run independent retinotopic localizers to improve the specificity of the conclusions about activation distribution between visual areas.

The main obstacle in the integration-by-prediction techniques is the access to the individual single trial ERPs, which are known to be noisy even in the environment outside the scanner. Traditionally, averaging across a large number of trials is used as ERP de-noising technique (Luck, 2005). Due to this tradition, single trial ERPs are too often neglected, while they do contain useful information that is potentially lost in averaging (Bagshaw and Warbrick, 2007). Alternative de-noising techniques include autocorrelation (Cerutti et al., 1988), wavelet decomposition (Warbrick et al., 2009), and ICA (Debener et al., 2005). In this study, subtraction of the ERPs of the same single trial at different electrodes was applied as de-noising technique. Since the lateralized visual stimuli are known to elicit larger and earlier responses for both P1 and N1 (Di Russo et al., 2002), the sign of the difference between the right and left hemispheres of the individual trial amplitude should predict the side of the stimulus. Indeed, our data showed that the prediction is significantly above chance at group level, even though individual variation is observable (Table 1). The single trial amplitude difference values can thus be used as regressors for the fMRI analysis.
One of the main limitations of the present study is that we did not get significant results in our random-effects group analysis for ERPrelated fMRI when correction for multiple comparisons was applied; instead, an uncorrected $p<0.001$ threshold was used. An uncorrected threshold is, however, often used in combined EEG-fMRI studies (e.g., Eichele et al., 2005; Karch et al., 2010). Given that our study is a methodological and explorative one, with a relatively small group size (14 participants), the threshold can be considered as acceptable.

We conclude that simultaneous EEG-fMRI measurements hold potential to suggest new perspectives in the study of peripheral vision. Our results suggest that visual processing in a spatial detection task at the latencies of 100-200 ms after stimulus onset is associated mostly with activation of temporo-occipital junction areas possibly within dorsal visual stream. We successfully used single-trial ERP information in our fMRI analysis. Yet, more research in single-trial denoising techniques is necessary for the development of further integration-by-prediction EEG-fMRI analysis.

\section{Acknowledgments}

This research is supported by the Research Council KUL: CoE EF/ 05/006 Optimization in Engineering (OPTEC), IDO 05/010 EEG-fMRI and GOA-MANET, FWO projects: G.0427.10N (Integrated EEG-fMRI); the Belgian Federal Science Policy Office IUAP P6/04 (DYSCO "Dynamical systems, control and optimization," 2007-2011) and the EU project Neuromath (COST-BM0601). Katrien Vanderperren is supported by a PhD grant from the Flemish Government (IWT). Maarten De Vos is supported by a K.U.Leuven postdoctoral fellowship. Nikolay Novitskiy is supported by a post-doctoral scholarship of Research Foundation-Flanders (FWO). Johan Wagemans is supported by a Methusalem grant by the Flemish Government (METH/08/02).

\section{References}

Allen, P.J., Josephs, O., Turner, R., 2000. A method for removing imaging artifact from continuous EEG recorded during functional MRI. Neuroimage 12, 230-239.

Assecondi, S., Vanderperren, K., Novitskiy, N., Ramautar, J.R., Fias, W., Staelens, S., Stiers, P., Sunaert, S., Van Huffel, S., Lemahieu, I., 2010. Effect of the static magnetic field of the MR-scanner on ERPs: evaluation of visual, cognitive and motor potentials. Clin. Neurophysiol. 121, 672-685.

Bagshaw, A.P., Warbrick, T., 2007. Single trial variability of EEG and fMRI responses to visual stimuli. Neuroimage 38, 280-292.

Becker, R., Ritter, P., Moosmann, M., Villringer, A., 2005. Visual evoked potentials recovered from fMRI scan periods. Hum. Brain Mapp. 26, 221-230.

Benar, C.G., Schon, D., Grimault, S., Nazarian, B., Burle, B., Roth, M., Badier, J.M., Marquis P., Liegeois-Chauvel, C., Anton, J.L., 2007. Single-trial analysis of oddball eventrelated potentials in simultaneous EEG-fMRI. Hum. Brain Mapp. 28, 602-613.

Bledowski, C., Prvulovic, D., Hoechstetter, K., Scherg, M., Wibral, M., Goebel, R., Linden, D.E., 2004. Localizing P300 generators in visual target and distractor processing: a combined event-related potential and functional magnetic resonance imaging study. J. Neurosci. 24, 9353-9360.

Bonmassar, G., Schwartz, D.P., Liu, A.K., Kwong, K.K., Dale, A.M., Belliveau, J.W., 2001 Spatiotemporal brain imaging of visual-evoked activity using interleaved EEG and fMRI recordings. Neuroimage 13, 1035-1043.

Calhoun, V.D., Adali, T., Pearlson, G.D., Kiehl, K.A., 2006. Neuronal chronometry of target detection: fusion of hemodynamic and event-related potential data. Neuroimage 30, 544-553.

Cerutti, S., Chiarenza, G., Liberati, D., Mascellani, P., Pavesi, G., 1988. A parametric method of identification of single-trial event-related potentials in the brain. IEEE Trans. Biomed. Eng. 35, 701-711.

Creem, S.H., Proffitt, D.R., 2001. Defining the cortical visual systems: "what," "where," and "how". Acta Psychol. (Amst.) 107, 43-68.

de Munck, J.C., Goncalves, S.I., Huijboom, L., Kuijer, J.P., Pouwels, P.J., Heethaar, R.M., Lopes da Silva, F.H., 2007. The hemodynamic response of the alpha rhythm: an EEG/ fMRI study. Neuroimage 35, 1142-1151.

Debener, S., Ullsperger, M., Siegel, M., Fiehler, K., von Cramon, D.Y., Engel, A.K., 2005 Trial-by-trial coupling of concurrent electroencephalogram and functional magnetic resonance imaging identifies the dynamics of performance monitoring. J Neurosci. 25, 11730-11737.

Debener, S., Ullsperger, M., Siegel, M., Engel, A.K., 2006. Single-trial EEG-fMRI reveals the dynamics of cognitive function. Trends Cogn. Sci. 10, 558-563.

Debener, S., Strobel, A., Sorger, B., Peters, J., Kranczioch, C., Engel, A.K., Goebel, R., 2007a Improved quality of auditory event-related potentials recorded simultaneously with 3-T fMRI: removal of the ballistocardiogram artefact. Neuroimage 34, 587-597.

Debener, S., Ullsperger, M., Siegel, M., Engel, A.K., 2007b. Towards single-trial analysis in cognitive brain research. Trends Cogn. Sci. 11, 502-503. 
Dehaene, S., Le Clec, H.G., Cohen, L., Poline, J.B., van de Moortele, P.F., Le Bihan, D., 1998 Inferring behavior from functional brain images. Nat. Neurosci. 1, 549-550.

Delorme, A., Makeig, S., 2004. EEGLAB: an open source toolbox for analysis of singletrial EEG dynamics including independent component analysis. J. Neurosci. Methods 134, 9-21.

Di Russo, F., Martinez, A., Sereno, M.I., Pitzalis, S., Hillyard, S.A., 2002. Cortical sources of the early components of the visual evoked potential. Hum. Brain Mapp. 15, 95-111.

Di Russo, F., Martinez, A., Hillyard, S.A., 2003. Source analysis of event-related cortica activity during visuo-spatial attention. Cereb. Cortex 13, 486-499.

Di Russo, F., Pitzalis, S., Spitoni, G., Aprile, T., Patria, F., Spinelli, D., Hillyard, S.A., 2005 Identification of the neural sources of the pattern-reversal VEP. Neuroimage 24 874-886.

Eichele, T., Specht, K., Moosmann, M., Jongsma, M.L., Quiroga, R.Q., Nordby, H., Hugdahl, K., 2005. Assessing the spatiotemporal evolution of neuronal activation with singletrial event-related potentials and functional MRI. Proc. Natl. Acad. Sci. U. S. A. 102, 17798-17803.

Eichele, T., Calhoun, V.D., Debener, S., 2009. Mining EEG-fMRI using independent component analysis. Int. J. Psychophysiol. 73, 53-61.

Haxby, J.V., Grady, C.L., Horwitz, B., Ungerleider, L.G., Mishkin, M., Carson, R.E Herscovitch, P., Schapiro, M.B., Rapoport, S.I., 1991. Dissociation of object and spatial visual processing pathways in human extrastriate cortex. Proc. Natl. Acad. Sci. U. S. A. 88, 1621-1625.

Karch, S., Feuerecker, R., Leicht, G., Meindl, T., Hantschk, I., Kirsch, V., Ertl, M., Lutz, J., Pogarell, O., Mulert, C., 2010. Separating distinct aspects of the voluntary selection between response alternatives: N2- and P3-related BOLD responses. Neuroimage $51,356-364$

Kilner, J.M., Mattout, J., Henson, R., Friston, K.J., 2005. Hemodynamic correlates of EEG: a heuristic. Neuroimage 28, 280-286.

Liu, Z., Zhang, N., Chen, W., He, B., 2009. Mapping the bilateral visual integration by EEC and fMRI. Neuroimage 46, 989-997.

Logothetis, N.K., Pauls, J., Augath, M., Trinath, T., Oeltermann, A., 2001. Neurophysiological investigation of the basis of the fMRI signal. Nature 412, 150-157.

Luck, S.J., 2005. An introduction to the event-related potential technique. The MIT Press, Cambridge, MA.

Mayhew, S.D., Dirckx, S.G., Niazy, R.K., Iannetti, G., Wise, R.G., 2009. EEG signatures of auditory activity correlate with simultaneously recorded fMRI responses in humans. Neuroimage 49, 849-864.

Mennes, M., Wouters, H., Vanrumste, B., Lagae, L., Stiers, P., 2010. Validation of ICA as a tool to remove eye movement artifacts from EEG/ERP. Psychophysiology 47, 1142-1150.
Mishkin, M., Ungerleider, L.G., Macko, K.A., 1983. Object vision and spatial vision-2 cortical pathways. Trends Neurosci. 6, 414-417.

Moosmann, M., Schonfelder, V.H., Specht, K., Scheeringa, R., Nordby, H., Hugdahl, K., 2009. Realignment parameter-informed artefact correction for simultaneous EEGfMRI recordings. Neuroimage 45, 1144-1150.

Mulert, C., Seifert, C., Leicht, G., Kirsch, V., Ertl, M., Karch, S., Moosmann, M., Lutz, J., Moller, H.J., Hegerl, U., Pogarell, O., Jager, L., 2008. Single-trial coupling of EEG and fMRI reveals the involvement of early anterior cingulate cortex activation in effortful decision making. Neuroimage 42, 158-168.

Niazy, R.K., Beckmann, C.F., Iannetti, G.D., Brady, J.M., Smith, S.M., 2005. Removal of FMRI environment artifacts from EEG data using optimal basis sets. Neuroimage 28, 720-737.

Sommer, M., Meinhardt, J., Volz, H.P., 2003. Combined measurement of event-related potentials (ERPs) and fMRI. Acta Neurobiol. Exp. (Wars) 63, 49-53.

Sunaert, S., Van Hecke, P., Marchal, G., Orban, G.A., 1999. Motion-responsive regions of the human brain. Exp. Brain Res. 127, 355-370.

Tootell, R.B., Mendola, J.D., Hadjikhani, N.K., Ledden, P.J., Liu, A.K., Reppas, J.B., Sereno, M.I., Dale, A.M., 1997. Functional analysis of V3A and related areas in human visual cortex. J. Neurosci. 17, 7060-7078.

Ullsperger, M., 2010. EEG-Informed fMRI Analysis. In: Ullsperger, M., Debener, S. (Eds.), Simultaneous EEG and fMRI: Recording, Analysis, and Application. Oxford University Press, New York, pp. 153-159.

Vanderperren, K., De Vos, M., Ramautar, J.R., Novitskiy, N., Mennes, M., Assecondi, S., Vanrumste, B., Stiers, P., Van den Bergh, B.R., Wagemans, J., Lagae, L., Sunaert, S., Van Huffel, S., 2010. Removal of BCG artifacts from EEG recordings inside the MR scanner: a comparison of methodological and validation-related aspects. Neuroimage 50, 920-934.

Wager, T.D., Nichols, T.E., 2003. Optimization of experimental design in fMRI: a general framework using a genetic algorithm. Neuroimage 18, 293-309.

Wandell, B.A., Dumoulin, S.O., Brewer, A.A., 2007. Visual field maps in human cortex. Neuron 56, 366-383.

Warbrick, T., Mobascher, A., Brinkmeyer, J., Musso, F., Richter, N., Stoecker, T., Fink, G.R., Shah, N.J., Winterer, G., 2009. Single-trial P3 amplitude and latency informed event-related fMRI models yield different BOLD response patterns to a target detection task. Neuroimage 47, 1532-1544.

Wilson, E.B., 1927. Probable inference, the law of succession, and statistical inference. J. Am. Stat. Assoc. 22, 209-212.

Wu, L., Eichele, T., Calhoun, V.D., 2010. Reactivity of hemodynamic responses and functional connectivity to different states of alpha synchrony: a concurrent EEGfMRI study. Neuroimage 52, 1252-1260. 